\title{
Erratum to: Quantitative evaluation of Tibet's resource and environmental carrying capacity
}

\author{
WANG Liang1,2,3 (D)https://orcid.org/oooo-0oo1-7906-2615; e-mail: wangl.17b@igsnrr.ac.cn \\ LIU Hui 1,4* iD https://orcid.org/oooo-0o01-9318-1696; ${ }^{\circledR}$ e-mail: liuh@igsnrr.ac.cn \\ * Corresponding author \\ 1 Key Laboratory of Regional Sustainable Development Modeling, Institute of Geographic Sciences and Natural \\ Resources Research, Chinese Academy of Sciences, Beijing 100101, China \\ 2 University of Chinese Academy of Sciences, Beijing 10oo49, China \\ 3 Faculty of Geographical Science, Beijing Normal University, Beijing 10o875, China \\ 4 College of Resource and Environment, University of Chinese Academy of Sciences, Beijing 10oo49, China \\ Citation: Wang L, Liu H (2019) Erratum to: Quantitative evaluation of Tibet's resource and environmental carrying \\ capacity. Journal of Mountain Science 16(8). https://doi.org/10.1007/s11629-018-5339-x
}

(C) Science Press, Institute of Mountain Hazards and Environment, CAS and Springer-Verlag GmbH Germany, part of Springer Nature 2019

\section{Erratum to: J. Mt. Sci. (2019) 16(7): 1702-1714}

https://doi.org/10.1007/s11629-018-5148-2

The 1st and the 2nd affiliations in the title page are incorrect in the original article. The correct ones should be as follows.

\footnotetext{
1 Key Laboratory of Regional Sustainable Development Modeling, Institute of Geographic Sciences and Natural Resources Research, Chinese Academy of Sciences, Beijing 100101, China

2 University of Chinese Academy of Sciences, Beijing 10oo49, China
}

The notes under Table 8 are incorrect in the original article. The correct ones should be as follows.

Notes: Gr stands for the yearly GDP growth rate; Pr stands for the annual growth rate of resident population. at https://doi.org/10.1007/s11629-018-5148-2. 